\title{
The Severity of Naloxone-Precipitated Opiate Withdrawal Is Attenuated by Felbamate, a Possible Glycine Antagonist
}

\author{
Therese A. Kosten, Ph.D., Jenine L. DeCaprio, B.S., and Marc I. Rosen, M.D.
}

Recent studies indicate that an N-methyl-D-aspartate (NMDA) receptor system in the rostral medulla is involved in opiate withdrawal. Although NMDA antagonists attenuate naloxone-precipitated opiate withdrawal, they can cause phencyclidine (PCP)like effects that contraindicate clinical use. Because NMDA channels contain sites for the glutamate coagonist, glycine, we assessed the effects of glycinergic agents on naloxone-precipitated opiate withdrawal in rats. The putative antagonist, felbamate $(100,300 \mathrm{mg} / \mathrm{kg})$, attenuated overall withdrawal severity in a dose-related

KEY WORDS: HA-966,D-cycloserine; Morphine; N-methylD-aspartate; Glutamate; Chronic drug effects; Glycine partial agonists

Opiate dependence remains a serious health problem in the United States today, and new, more effective treatments are needed. One treatment approach is to use pharmacologic agents during opiate detoxification to attenuate the severity of opiate withdrawal and, possibly, as long-term maintenance treatments, to attenuate protracted withdrawal symptoms.

Potential pharmacologic treatments for opiate withdrawal are agents that act at N-methyl-D-asparate (NMDA)/glutamate receptor systems. Activation of these systems is associated with seizures and neurotoxicity (Bowyer 1982; McNamara et al 1988; Simon et al.

From the Division of Substance Abust, Department of Psychiatry Yale University School of Medicine, New: Haven. Connecticut

Address correspondence to: Therese A. Kosten. Ph.D., Division of Substance Abuse, Connecticut Mental Health Center, 34 Park Street, Room S305, New Haven, CT 06508

Received December 8, 1994; revised March 9. 1445 accepted March 27, 1995. manner and reduced occurrences of chews, teeth chatters, and penile grooming. The partial agonist, D-cycloserine (.3. $10 \mathrm{mg} / \mathrm{kg}$ ), attenuated withdrawal severity, but not in a dose-related manner. Conversely, the low dose of the partial agonist, ( \pm )-HA-966 (3, $10 \mathrm{mg} / \mathrm{kg})$, heightened the occurrences of some withdrawal signs. These results support a role for glycine in opiate withdrawal and suggest that these agents, which do not cause PCPlike effects, may be potential treatment for agents for opiate detoxification. [Neuropsychopharmacology 13:323$333,1995]$

$1984)$ and is involved in a variety of plasticity phenomena, including long-term potentiation (Collingridge et al. 1983; Harris et al. 1984; Morris et al. 1986) and developmental plasticity (Kleinschmidt et al. 1987; Rauschecker and Hahn 1987; Lincoln et al. 1988). Neural and behavioral alterations occur with chronic exposure to opiates - with one such plasticity phenomenon being the presence of withdrawal signs when the opiate is discontinued or when an opiate antagonist, such as naloxone, is given. The expression of opiate withdrawal appears to involve the NMDA/glutamate system, as suggested by recent neurobiologic research. There is an excitatory input from the nucleus paragigantocellularis (PGi), a group of glutamate-containing neurons in the rostral medulla (Ennis and Aston-Jones 1988), to the locus coeruleus (LC), a group of noradrenergic cells that show hyperexcitability during opiate withdrawal (Aghajanian 1978; Rasmussen and Aghajanian 1989). Glutamate and aspartate levels in the LC are enhanced after intracerebroventricular (Zhang et al. 1994) or systemic (Aghajanian et al. 1994) administration of opiate antagonists to morphine-exposed rats. 
Lesions of the PGi (Rasmussen and Aghajanian 1989), as well as intracerebroventricular (Rasmussen and Aghajanian 1989; Rasmussen et al. 1991b) or local (Akaoka and Aston-Jones 1991) infusions of excitatory amino acid antagonists, attenuate the antagonistinduced LC activation in morphine-exposed rats and attenuate the behavioral signs of withdrawal (Rasmussen et al. 1991b). Systemic administration of the noncompetitive, NMDA antagonist, MK-801, attenuates naloxone-precipitated opiate withdrawal in rodents (Rasmussen et al. 1991a; Tanganelli et al. 1991; Higgins et al. 1992). However, clinical use is contraindicated because many NMDA antagonists lead to phencyclidine (PCP)like effects, such as ataxia and behavioral agitation (Willets et al. 1990).

The NMDA-responsive glutamate receptor is part of an ion channel complex that contains a strychnineinsensitive glycine receptor site (Johnson and Ascher 1977). Glycine is considered a coagonist at these receptors as it enables the NMDA receptor complex to become activated by glutamate (Thomson 1990). It has been suggested recently that glycine antagonists or lowefficacy partial agonists may have anticonvulsant and neuroprotective effects without causing PCPlike effects (Kemp and Leeson 1993). By extension then, glycine antagonists would be predicted to attenuate naloxoneprecipitated opiate withdrawal without causing $\mathrm{PCP}$ like behavioral effects. This suggests an alternative pharmacologic approach to test for potential treatment agents for opiate abuse and withdrawal.

As a first step in testing whether pharmacologic manipulation of the strychnine-insensitive glycine system would alter antagonist-precipitated opiate withdrawal, we assessed the effects of three agents with presumed glycinergic properties on the severity of naloxoneprecipitated opiate withdrawal in morphine-exposed rats. This study was also designed to inform directly the potential clinical use of glycine agents. Thus, two of the agents assessed can be used clinically.

Felbamate (2-phenyl-1,3-propanediol dicarbamate; Carter-Wallace, Cranbury, NJ) is an anticonvulsant with neuroprotective properties. Its anticonvulsant effects have been demonstrated in mice (Swinyard et al. 1986; Gordon et al. 1991; White et al. 1992), rats (Swinyard et al. 1986; White et al. 1992), rhesus monkeys (Perhach et al. 1986), and in humans with epilepsy (Leppik et al. 1991; Theodore et al. 1991; Sachdeo et al. 1992; Ritter et al. 1993). Felbamate has neuroprotective effects in that it protects against tissue damage after hypoxia and ischemia in rodents (Wallis et al. 1990, 1992; Wasterlain et al. 1992; Chronopoulos et al.1993). The neural mechanisms underlying these effects of felbamate are poorly understood. However, a recent study suggests that felbamate has glycine antagonist properties because the binding interaction of felbamate with glycine recep- tors agrees well with its brain and plasma levels (McCabe et al. 1993). Moreover, felbamate reduced seizures and other behavioral effects of kainic acid administration that may have produced excitation by its actions at NMDA/glutamate receptors (Chronopoulos et al. 1993).

D-cycloserine, an antibiotic, is a partial glycine agonist (Hood et al. 1989; Emmett et al. 1991) with a potency about $40 \%$ to $50 \%$ of the full agonists, glycine or D-serine (Hood et al. 1989; Watson et al. 1990). D-cycloserine has enhanced performance in spatial learning tasks in intact (Monahan et al. 1989) and hippocampal-lesioned (Schuster and Schmidt 1992) rats. Finally, we also tested the effects of the partial glycine agonist, 1-hydroxy-3-aminopyrrolidone-2 or, ( \pm )HA-966, on severity of naloxone-precipitated opiate withdrawal. HA-966 protects selectively against NMDAmediated neural damage (McDonald et al. 1989). These neuroprotective and other effects of HA-966 may be due to its glycine antagonist properties. HA- 966 has affinity for the strychnine-insensitive glycine binding site (Foster and Kemp 1989) and its antagonism of NMDA is reversed by glycine (Fletcher and Lodge 1988). Thus, we predicted that the putative glycine antagonist, felbamate, would attenuate the severity of naloxoneprecipitated opiate withdrawal, whereas the partial agonists, D-cycloserine and HA-966, might enhance withdrawal severity. Alternatively, if D-cycloserine and HA-966 act more as low efficacy partial agonists, they may also attenuate opiate withdrawal, as discussed previously (Kemp and Leeson 1993).

\section{METHODS}

\section{Animals and Housing}

Forty-eight, male Sprague-Dawley rats (CAMM, Wayne, $\mathrm{NJ}$ ) weighing about $350 \mathrm{~g}$ at the start of the experiment were used in this study. These rats were divided into eight groups ( $n=6$ each) to test the effects of various doses of the three glycine agents on naloxone-precipitated opiate withdrawal. Rats were group-housed (three to a cage) in wire-mesh cages in a temperature-controlled colony colony room with a 12:12 light/dark cycle (lights on at 0700 hours). Food (Purina chow) and water were available ad libitum. All procedures were approved by the Yale Animal Care and Use Committee at Yale University School of Medicine (New Haven, CT).

\section{Drugs}

Felbamate was suspended in a $50 \%$ solution of polyethylene glycol 400 in sterile water based on the methods of Gordon et al. (1991). Felbamate was administered in a volume of $10 \mathrm{ml} / \mathrm{kg}$ body weight and injected (IP), in separate groups of rats, at one of the following 
doses: 0 (vehicle), 100 , and $300 \mathrm{mg} / \mathrm{kg}$. This dose range was chosen based on previous research for which this range had effective anticonvulsant and neuroprotective effects (Chronopoulos et al. 1993; Swinyard et al. 1986; Wasterlain et al. 1992). D-cycloserine and ( \pm )-HA-966 (Research Biochemicals, Inc.) were dissolved in isotonic saline and administered in a volume of $1 \mathrm{ml} / \mathrm{kg}$ body weight. The doses of D-cycloserine and $( \pm)$-HA-966 used, in separate groups of rats, were 3 and $10 \mathrm{mg} / \mathrm{kg}$. One vehicle control group that received isotonic saline injections was used for both of these drugs. The dose range for $\mathrm{D}$-cycloserine was based on previous research that found effective results in spatial learning tasks (Monahan et al. 1989; Schuster and Schmidt 1992). The dose range for $( \pm)$-HA- 966 was based on previous research (Danysz et al. 1994; McDonald et al. 1989), and low doses were used to avoid heavy sedation (Brett Morrow, personal communication, August 1994). Naloxone $(10 \mathrm{mg} / \mathrm{kg}, \mathrm{SC})$ was dissolved in isotonic saline and administered in a volume of $1 \mathrm{ml} / \mathrm{kg}$.

\section{Opiate Withdrawal Procedure}

All rats were implanted SC with three morphine pellets (75 mg; National Institute on Drug Abuse, Rockville, MD) under light (Halothane) anesthesia. Two pellets were implanted in the thigh on day 1 , and one pellet was implanted in the opposite thigh on day 2. On day 4, rats were injected with naloxone $(10 \mathrm{mg} / \mathrm{kg}$, $\mathrm{SC}$ ) to induce withdrawal. One hour (felbamate) or 30 minutes prior to the naloxone injection (D-cycloserine and ( \pm )-HA-966), glycine agents were given for one of the dose groups described previously. The rats were then placed into a clear, Plexiglas observation tank ( 18 $\mathrm{L} \times 9^{\prime \prime} \mathrm{W} \times 8^{\prime \prime} \mathrm{H}$ ) and rated for withdrawal severity for the next 60 minutes by a rater who was blind to treatment condition.

The withdrawal signs rated are presented in Tables 1,2 , and 3 . Most signs were rated on a 4-point scale ( 0 , not present; 1 , mild; 2 , moderate; and 3 , severe) for four contiguous 15 -minute time periods $(60$ minutes total), based on the method of Bläsig et al. (1973) and used in our previous work on naloxone-precipitated opiate withdrawal (Kosten 1990). Diarrhea and irritability (defined as vocalization when touched at the end of the time period) were rated as absent ( 0 ) or present (1) during these four time periods. In addition, the frequencies of bouts of chewing, teeth chatters, wet dog shakes, penile grooming, and stretches were tabulated. (A bout of teeth chatters ends typically with chewing; these chewing occurrences were not included in the chewing tabulation.) These signs were rated for withdrawal severity and assessed in the total withdrawal score based on their frequency of occurrence, in the following manner. For chewing and teeth chatters, ratings were defined as 0 (no occurrences), 1 (10 or fewer occurrences), 2 (11 to 20 occurrences), and 3 (21 or more occurrences). For wet dog shakes and penile grooming, ratings were defined as 0 (no occurrences), 1 (4 or fewer occurrences), 2 ( 5 to 8 occurrences), and 3 ( 8 or more occurrences). Lacrimation/rhinorrhea, salivation, and ptosis were rated at each time period as new occurrences (i.e., ratings were not based on what had occurred in an earlier time period). Body weight loss was assessed by subtracting the body weight immediately after the 60-minute rating period from that before the injection of the pretreatment drug. Finally, rats were observed for evidence of certain nonopiate withdrawal behaviors including sedation and the PCP-like effects of behavioral agitation, head weaving, and ataxia.

\section{Data Analysis}

Opiate withdrawal ratings for each sign were summed for each of the four 15-minute time periods. These scores were analyzed, individually for each treatment agent, using analysis of variance (ANOVA) with dose as a group factor and time as a repeated measure. The scores for each individual sign (lacrimation/rhinorrhea, salivation, ptosis, diarrhea, and irritability) and the frequency of each sign (chewing, teeth chatters, wet dog shakes, penile grooming, and stretches) were summed across the four time periods to compare the effects of the treatment agents on specific signs of naloxone-precipitated opiate withdrawal. These summed scores were analyzed by a one-way ANOVA, individually by treatment agent, for dose effects. When significant dose effects were found in the felbamate study, linear contrast statements were used to describe further this effect. In addition, because the doses used of the partial agonists, D-cycloserine and HA-966, may result in an enhancement of withdrawal severity at the lower dose and an attenuation at the higher dose, quadratic contrasts were performed on the withdrawal data when trends or significant effects were seen.

\section{RESULTS}

\section{Felbamate Study}

Three separate groups of rats were treated with vehicle or one dose $(100$ or $300 \mathrm{mg} / \mathrm{kg}$ ) of felbamate $60 \mathrm{~min}$ utes prior to naloxone injections, and ratings of withdrawal signs were tabulated for four contiguous 15minute time periods. The sum of the severity ratings of opiate withdrawal for each of the four 15-minute time periods are presented in Figure 1. As shown in this figure, felbamate attenuated the severity of naloxoneprecipitated opiate withdrawal in a dose-dependent manner. That is, the vehicle rats showed the greatest 


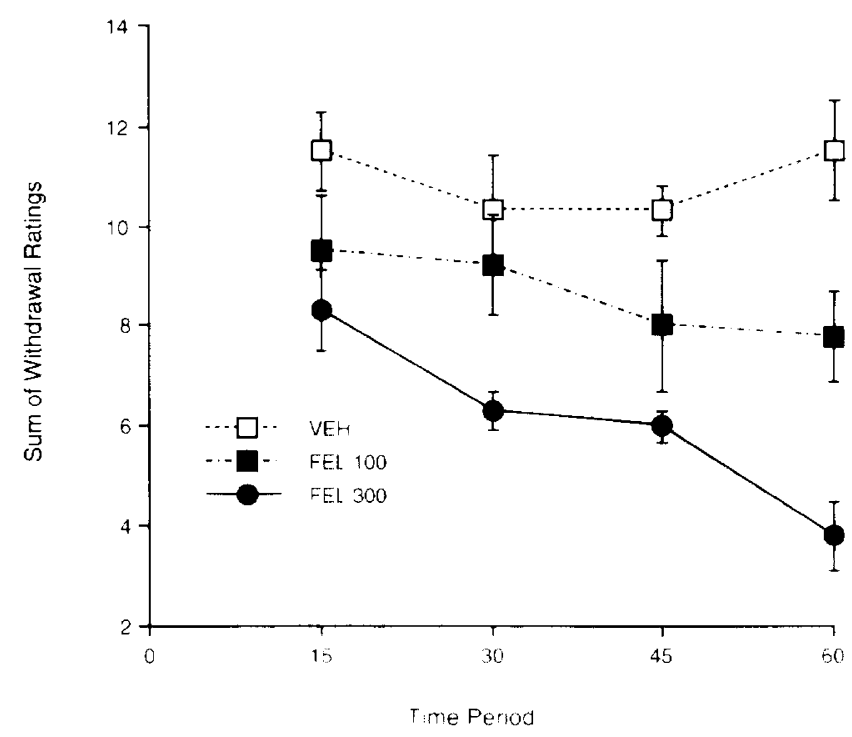

Figure 1. The sum of the severity ratings of the individual withdrawal signs across the four 15 -minute time periods is shown. Naloxone was given at 0 minutes. Felbamate ( 100 and $300 \mathrm{mg} / \mathrm{kg}$; closed symbols) lead to a dose-dependent attenuation in the severity of naloxone-precipitated opiate withdrawal compared to vehicle (open squares) treatment.

degree of withdrawal severity. Withdrawal severity was less in the $100 \mathrm{mg} / \mathrm{kg}$ felbamate dose group and was even lower in the group treated with the $300 \mathrm{mg} / \mathrm{kg}$ dose of felbamate. This statement is supported by the significant dose effect, $F(2,15)=13.33 ; p<.001$ and the significant linear contrast statement, $F(1,15)=26,65$; $p<.0001$.

As shown in Figure 1, the severity of naloxoneprecipitated opiate withdrawal decreased over time, particularly in the $300 \mathrm{mg} / \mathrm{kg}$ felbamate dose group. These statements are supported by the significant time effect, $F(3,45)=5.23 ; p<.01$ and the significant dose $\times$ time interaction, $F(6,45)=2.36 ; p=.05$. Examination of the data suggests that the withdrawal severity decreased over time from the 15 - to the 30 -minute time period for all groups and from the 45 - to the 60-minute time period for the $300 \mathrm{mg} / \mathrm{kg}$ felbamate group

Table 1 presents the mean ( \pm SEM) number of occurrences of the withdrawal signs of chewing, teeth chatters, wet dog shakes, penile grooming, and stretches by the felbamate dose group. There were significant group differences in chewing, $F(2,15)=5.77 ; p<.02$; teeth chatters, $F(2,15)=5.20 ; p<.02$, and penile grooming, $F(2,15)=12.65 ; p<.001$. In all cases, the greatest frequencies of these signs were seen in the vehicle group and the least frequencies were seen in the $300 \mathrm{mg} / \mathrm{kg}$ felbamate dose group. These statements are supported by linear contrast statements: chewing, $F(1,15)=11.33 ; p<.005$; teeth chatters, $F(1,15)=10.34$; $p<.01$; and penile grooming, $F(1.15)=21.62 ; p<.001$.
The sum of the severity ratings across the four time periods for ptosis, salivation, lacrimation/rhinorrhea, diarrhea, and irritability is also shown in Table 1. There was a trend for group differences in salivation, $F(2,15)=3.15 ; p<.10$. Again, the greatest severity for this sign was seen in the vehicle group and the least severity was shown for the $300 \mathrm{mg} / \mathrm{kg}$ felbamate dose group. This was supported by the significant linear contrast statement, $F(1,10)=6.18 ; p<.05$. Finally, body weight loss after naloxone is presented in Table 1. All three groups showed some weight loss; however, this and all other withdrawals signs did not show group differences $(p>.10)$.

\section{D-cycloserine Study}

Three groups of rats were treated with vehicle or one dose ( 3 or $10 \mathrm{mg} / \mathrm{kg}$ ) of $\mathrm{D}$-cycloserine 30 minutes prior to naloxone injection, and ratings of withdrawal signs were tabulated for four contiguous 15-minute time periods. The sum of the severity ratings of opiate withdrawal for each of the four 15-minute time periods is presented in Figure 2. As shown in this figure, D-cycloserine attenuated the severity of naloxone-precipitated opiate withdrawal, as supported by the significant dose effect, $F(2,15)=4.23 ; p<.05$. However, D-cycloserine treatment did not appear to attenuate naloxone-precipitated opiate withdrawal in a dose-dependent manner. Moreover, neither a linear nor a quadratic contrast explained the data in a significant manner $(p>.10)$. There was a trend for a significant time effect, $F(3,45)=$ $2.54 ; p<.10$, which probably reflects the decrease in withdrawal severity at the 30 -minute time period for all groups. The dose $\times$ time interaction did not reach significance.

Table 2 presents the mean ( \pm SEM) number of occurrences of the withdrawal signs of chewing, teeth chatters, wet dog shakes, penile grooming, and stretches by $D$-cycloserine dose group. The sum of the severity ratings across the four time periods for ptosis, salivation, lacrimation/rhinorrhea, diarrhea, and irritability is also shown in Table 2. Finally, body weight loss after naloxone is presented in Table 2. All three groups showed weight loss; however, this and all the withdrawal signs did not show group differences.

\section{HA-966 Study}

Two groups of rats were treated with one dose $(3$ or $10 \mathrm{mg} / \mathrm{kg}$ ) of $( \pm)$-HA-966 30 minutes prior to naloxone injection, and ratings of withdrawal signs were tabulated for four contiguous 15-minute time periods. Because the vehicle for ( \pm )-HA-966 was the same as that used for the D-cycloserine study, the results from the $( \pm)$-HA-966 groups are compared to the vehicle group 
Table 1. Effects of Felbamate on the Frequencies and Severity Ratings of Naloxone-Precipitated Opiate Withdrawal by Dose Group

\begin{tabular}{|c|c|c|c|c|}
\hline \multirow[b]{2}{*}{ Sign } & \multicolumn{3}{|c|}{ Group } & \multirow[b]{2}{*}{$p$} \\
\hline & Vehicle & $100 \mathrm{mg}$ & $300 \mathrm{mg}$ & \\
\hline \multicolumn{5}{|c|}{$\begin{array}{l}\text { Frequencies of withdrawal } \\
\text { signs }\end{array}$} \\
\hline Chewing & $20.7 \pm 3.6$ & $15.7 \pm 2.7$ & $7.8 \pm 1.2$ & 0.02 \\
\hline Teeth chatter & $37.4 \pm 6.1$ & $27.3 \pm 4.1$ & $13.9 \pm 5.1$ & 0.02 \\
\hline Wet dog & $4.8 \pm 2.1$ & $3.0 \pm 1.3$ & $1.7 \pm 0.9$ & NS \\
\hline Penile groom & $1.2 \pm 0.2$ & $1.0 \pm 0.3$ & 0 & 0.001 \\
\hline Stretch & $12.3 \pm 4.8$ & $5.8 \pm 2.2$ & $10.5 \pm 7.1$ & NS \\
\hline \multicolumn{5}{|l|}{ Total severity ratings } \\
\hline Ptosis & $9.0 \pm 0.8$ & $9 . \overline{5} \pm 0.6$ & $9.7 \pm 0.4$ & NS \\
\hline Salivation & $2.2 \pm 0.9$ & $1.3 \pm 0.5$ & $0^{-}$ & 0.10 \\
\hline Lacrimation & $1.5 \pm 1.0$ & $1.3 \pm 1.0$ & 0 & NS \\
\hline Diarrhea $^{a}$ & $0.8 \pm 0.7$ & $0.8 \pm 0.5$ & 0 & NS \\
\hline Irritability & $2.0 \pm 0.7$ & $1.0 \pm 0.5$ & $0.7 \pm 0.2$ & NS \\
\hline Body weight loss $(\mathrm{g})$ & $-10.3 \pm 3.1$ & $-7.8 \pm 1.2$ & $-4.5 \pm 1.2$ & NS \\
\hline
\end{tabular}

"These signs rated on a 2-point scale (0, absent, I present); all other signs rated on a 4-point scale (0), absent; 1 mild, 2; moderate; 3 , severe)

presented in the D-cycloserine study previously. The sum of the severity ratings of opiate withdrawal for each of the four 15-minute time periods is presented in Figure 3. As shown in this figure, there were no group differences in the overall severity of naloxone-precipitated opiate withdrawal across the four 15-minute time periods in this study $(p>.10)$. There was a significant effect of time, $F(3,45)=4.00 ; p<.05$, which probably

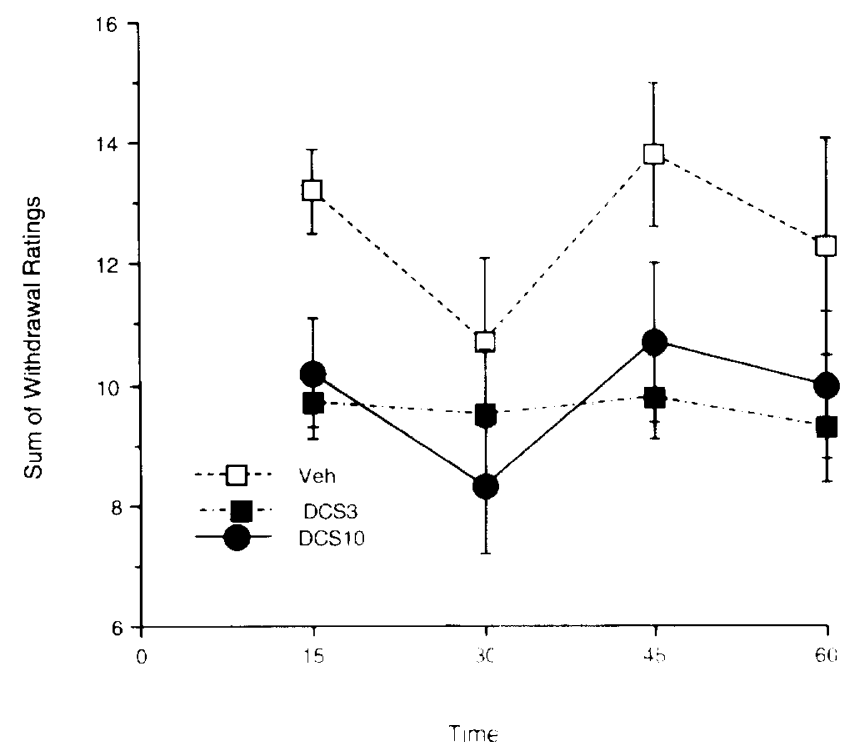

Figure 2. The sum of the severity ratings of the individual withdrawal signs across the four 15-minute time periods is shown. Naloxone was given at 0 minutes. D-cycloserine ( 3 and $10 \mathrm{mg} / \mathrm{kg}$; closed symbols) lead to a significant attenuation in the severity of naloxone-precipitated opiate withdrawal compared to vehicle (open squares) treatment. This effect was not dose-related. reflects the slight decrease in withdrawal severity observed at the 30-minute time period in most dose groups (see Figure 3).

Table 3 presents the mean $( \pm$ SEM) number of occurrences of the withdrawal signs of chewing, teeth chatters, wet dog shakes, penile grooming, and stretches by $( \pm)$ HA-966 dose group. There was a significant group difference in the number of occurrences of stretches, $F(2,15)=3.62 ; p=.05$, and a trend for a group difference in the number of occurrences of penile grooming, $F(2,15)=3.16 ; p=.07$. Further examination of the data suggests that these trends may be due to enhanced occurrences of these signs in the low dose ( $3 \mathrm{mg} / \mathrm{kg}$ ) HA-966 group. Post-hoc, quadratic contrasts supported this supposition for stretches, $F(1,10)=6.87$; $p<.02$, and for penile grooming, $F(1,10)=4.74 ; p<$ 05 . The sum of the severity ratings across the four time periods for ptosis, salivation, lacrimation/rhinorrhea, diarrhea, and irritability are also presented in Table 3. Finally, body weight loss after naloxone is presented in Table 3. All three groups showed weight loss; however, this and all other withdrawal signs showed no group differences $(p>.10)$.

\section{Drug Comparisons and Nonopiate Withdrawal Behaviors}

There were marked differences in the expression of some naloxone-precipitated opiate withdrawal signs among the three agents tested. Statistical comparisons of the two vehicle groups (polyethylene glycol versus saline) showed that there were significant differences in diarrhea, $F(1,10)=5.55 ; p .05$; body weight loss, $F(1,10)=11.18 ; p<.01$; salivation, $F(1,10)=5,74$; 
Table 2. Effects of D-cycloserine on the Frequencies and Severity Ratings of Naloxone-Precipitated Opiate Withdrawal by Dose Group

\begin{tabular}{lrrr}
\hline & \multicolumn{3}{c}{ Group } \\
\cline { 2 - 4 } Sign & Vehicle & $\mathbf{3} \mathbf{~ m g}$ & $\mathbf{1 0} \mathbf{~ m g}$ \\
\hline $\begin{array}{l}\text { Frequencies of withdrawal } \\
\quad \text { signs }\end{array}$ & & \\
Chewing & & & \\
Teeth & $15.5 \pm 5.9$ & $17.3 \pm 10.4$ & $14.2 \pm 6.1$ \\
Wet dog & $315 \pm 7.1$ & $29.8 \pm 7.2$ & $28.2 \pm 4.0$ \\
Penile & $5.5 \pm 1.1$ & $6.5 \pm 1.2$ & $4.3 \pm 1.1$ \\
Stretch & $0.6 \pm 0.3$ & $0.3 \pm 0.2$ & $0.5 \pm 0.2$ \\
Total severity ratings & $12 \pm 0.8$ & $2.3 \pm 2.0$ & $0.5 \pm 0.5$ \\
Ptosis & & & \\
Salivation & $4.2 \pm 0.7$ & $8.7 \pm 0.7$ & $10.3 \pm 0.4$ \\
Lacrimation & $6.0 \pm 1.3$ & $5.2 \pm 1.1$ & $6.0 \pm 1.3$ \\
Diarrhea & $4.7 \pm 0.8$ & $3.2 \pm 0.7$ & $4.0 \pm 0.9$ \\
Irritability & $2.7 \pm 0.6$ & $3.0 \pm 0.5$ & $1.8 \pm 0.6$ \\
Body weight loss $(g)$ & $3.0 \pm 0.6$ & $0.7 \pm 0.2$ & $3.2 \pm 0.3$ \\
\hline
\end{tabular}

"These signs rated on a 2-point scale (0), absent; 1 . present); all other signs rated on a 4-point scale (0) absent 1 mild; 2 , moderate; 3 , severe)

$p<.05$; lacrimation, $F(1,10)=6.16 ; p<.05 ;$ and stretches, $F(1,10)=5.25 ; p<.05$. By comparing the data obtained from the vehicle groups presented in Tables 1 and 2 , it can be seen that diarrhea, body weight loss, salivation, and lacrimation were less severe in the felbamate vehicle (polyethylene glycol) group compared to the isotonic saline vehicle group (see Table 2 or 3 ). Ratings of stretches were greater in the felbamate vehicle group compared to the saline vehicle group. Yet,

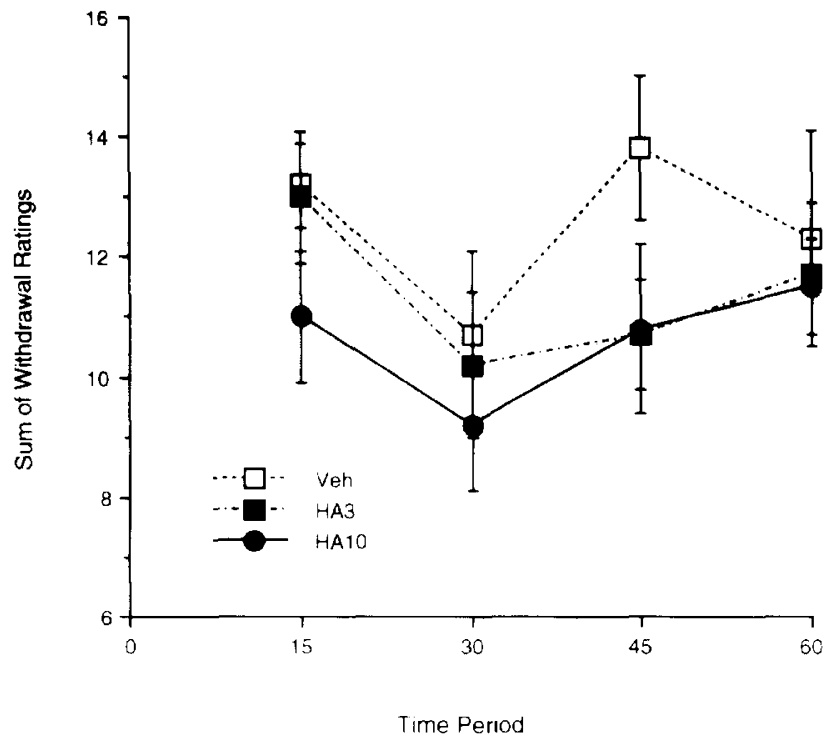

Figure 3. The sum of the severity ratings of the individual withdrawal signs across the four 15-minute time periods is shown. Naloxone was given at 0 minutes. HA-966 had no effect on the overall severity of naloxone-precipitated opiate withdrawal. overall withdrawal severity ratings did not differ between these two vehicle groups $(p>.10)$.

No signs of PCPlike behaviors, such as behavioral agitation, head weaving, or ataxia, were observed for any of the three agents tested. Sedation did occur in two of the six rats given the high dose of $( \pm)$-HA-966, but this effect was not observed in the felbamate or D-cycloserine groups.

\section{DISCUSSION}

The results of the present study show that felbamate attenuates the overall severity of naloxone-precipitated opiate withdrawal in a dose-dependent manner. Although the neural mechanisms underlying this and other effects of felbamate are not clear, there is some evidence that felbamate is a glycine antagonist (McCabe et al. 1993). D-cycloserine, which also has effects on the strychnine-insensitive glycine site, also attenuates naloxone-precipitated opiate withdrawal. However, this effect is not dose-related. In contrast to the results with these two agents, the low dose of the partial glycine agonist, $( \pm)$-HA-966, tends to enhance some naloxone-precipitated opiate withdrawal signs, although overall precipitated opiate withdrawal severity is not affected. These results suggest that the degree of expression of naloxone-precipitated opiate withdrawal is influenced by agents that have actions at the strychnine-insensitive glycine site.

Strychnine-insensitive glycine sites are located on $\mathrm{N}$-methyl-D-aspartate (NMDA) channels. Glycine permits these channels to be activated by glutamate and is considered a coagonist of glutamate (Thomson 1990). Glutamate-containing neurons of the PGi that pro- 
Table 3. Effects of ( \pm )-HA-966 on the Frequencies and Severity Ratings of Naloxone-Precipitated Opiate Withdrawal by Dose Group

\begin{tabular}{|c|c|c|c|c|}
\hline \multirow[b]{2}{*}{ Sign } & \multicolumn{3}{|c|}{ Group } & \multirow[b]{2}{*}{$p$} \\
\hline & Vehicle & $3 \mathrm{mg}$ & $10 \mathrm{mg}$ & \\
\hline \multicolumn{5}{|c|}{$\begin{array}{l}\text { Frequencies of withdrawal } \\
\text { signs }\end{array}$} \\
\hline Chewing & $15.5 \pm 5.9$ & $39.5 \pm 12.3$ & $40.8 \pm 9.4$ & NS \\
\hline Teeth & $31.5 \pm 7.1$ & $47.2 \pm 12.4$ & $37.8 \pm 12.7$ & NS \\
\hline Wet dog & $5.5 \pm 1.1$ & $7.8 \pm 1.9$ & $5.3 \pm 2.1$ & NS \\
\hline Penile & $0.6 \pm 0.3$ & $2.0 \pm 0.4$ & $1.3 \pm 0.4$ & $0.05^{a}$ \\
\hline Stretch & $1.2 \pm 0.8$ & $3.8 \pm 1.4$ & $0.3 \pm 0.3$ & $0.02^{a}$ \\
\hline \multicolumn{5}{|l|}{ Total severity ratings } \\
\hline Ptosis & $9.2 \pm 0.7$ & $7.8 \pm 0.9$ & $9.0 \pm 0.9$ & NS \\
\hline Salivation & $6.0 \pm 1.3$ & $6.2 \pm 0.9$ & $6.3 \pm 1.0$ & NS \\
\hline Lacrimation & $4.7 \pm 0.8$ & $3.8 \pm 1.4$ & $5.0 \pm 1.3$ & NS \\
\hline Diarrhea $^{h}$ & $2.7 \pm 0.6$ & $3.0 \pm 0.4$ & $3.3 \pm 0.3$ & NS \\
\hline Irritability ${ }^{t}$ & $3.0 \pm 0.6$ & $3.5 \pm 0.2$ & $3.3 \pm 0.3$ & NS \\
\hline Body weight loss (g) & $-21.7 \pm 1.4$ & $-21.8 \pm 1.5$ & $-25.2 \pm 1.6$ & NS \\
\hline
\end{tabular}

\footnotetext{
"p-values based on quadratic contrast of the dose effect

b These signs rated on a 2-point scale (0, absent; 1 . present); all other signs rated on a 4-point scale (0, absent; 1 , mild; 2 , moderate; 3 , severe).
}

ject to the noradrenergic neurons of the LC have been found to be related to opiate withdrawal. Specifically, glutamate levels in the LC are enhanced during antagonist-precipitated opiate withdrawal (Aghajanian et al. 1994; Zhang et al. 1994) and lesions of the PGi block the antagonist-induced excitation of the LC (Rasmussen and Aghajanian 1989). Because glycine is considered a coagonist of glutamate release, antagonism of glycine would be predicted to attenuate opiate withdrawal by decreasing the ability of glutamate to act at these ion channel complexes. Conversely, glycine agonists that further promote the actions of glutamate may be associated with heightened withdrawal severity. The results of the present set of studies using glycinergic agents are, for the most part, consistent with this model of opiate withdrawal.

Felbamate, an anticonvulsant, has recently been suggested to possess glycine antagonist properties (Chronopoulos et al. 1993; McCabe et al. 1993) and, thus, would be predicted to attenuate opiate withdrawal. The overall severity of naloxone-precipitated withdrawal was attenuated in a dose-related manner by felbamate in the present study. This effect of felbamate became stronger as the time past naloxone injection increased, particularly at the higher dose of felbamate. Felbamate, which was given 60 minutes prior to the naloxone injection, readily crosses the blood-brain barrier (Cornford et al.1992). Thus, it should be acting in the central nervous system by the time the withdrawal was induced. That the attenuation effect was weaker at the earlier time point ( 15 minutes), compared to the later time points, may reflect the intensity of withdrawal-induced activation seen at this point. In general, rats showed a great deal of activity almost immediately after the naloxone injection including wetdog shakes, teeth chatters, chewing, and penile grooming. By 30 minutes, much of this activity was reduced and more of the secretory signs, such as ptosis, salivation, and lacrimation, began to be exhibited. At later time points ( 45 to 60 minutes), teeth chatters and chews began to increase again.

The partial glycine agonist, D-cycloserine, led to a significant attenuation of the overall severity of naloxoneprecipitated opiate withdrawal. In general, the lower degree of overall withdrawal severity in both D-cycloserine dose groups was similar across all four 15-minute time periods, unlike the time and dose effects seen in the felbamate study. D-cycloserine also differed from felbamate in that there were no significant effects on ratings of individual withdrawal signs. We predicted D-cycloserine might enhance naloxone-precipitated withdrawal severity based on the suggestion that low efficacy partial glycine agonists may have neuroprotective and anticonvulsant effects (Kemp and Leeson 1993) and the extension of this supposition to naloxone-precipitated opiate withdrawal. That there was an attenuation in naloxone-precipitated withdrawal severity suggested that these doses of $\mathrm{D}$-cycloserine were acting as antagonists at these glycine sites, an effect to be expected from low efficacy partial agonists or higher doses of a partial agonist. The doses of $\mathrm{D}$-cycloserine used in this study ( 3 and $10 \mathrm{mg} / \mathrm{kg}$ ) were based on the literature that assessed this agent as a potential "cognitive enhancer." That is, within this dose range, $\mathrm{D}$-cycloserine increased performance in spatial tasks, in intact (Monahan et al. 1989) and hippocampal-lesioned rats (Schus- 
ter and Schmidt 1992). The data from these two earlier studies suggested that the doses of D-cycloserine were acting as agonists at glycine sites thus, enhancing the actions of glutamate in contrast to the results of the present study in which D-cycloserine appeared to have glycine antagonist actions. Perhaps, D-cycloserine was more potent at the glutamate system in the rostral medulla where the withdrawal attenuation effect likely occurs as compared to the glutamate system in the hippocampal region that likely underlies spatial learning tasks. This potency may reflect that glutamate levels are higher during precipitated opiate withdrawal as compared to during performance of spatial tasks. Or, D-cycloserine may have effects in other neural systems that underlie the attenuation of naloxone-precipitated withdrawal severity.

The third pharmacologic agent used in the present study to assess the role of glycine in naloxone-precipitated opiate withdrawal was ( \pm )-HA-966. HA-966, a partial glycine agonist, possesses affinity for the strychnine-insensitive glycine binding site on the NMDA receptor complex (Foster and Kemp 1989), and glycine reverses the ability of HA-966 to antagonize NMDA responses (Fletcher and Lodge 1988). At the doses chosen for the present study, ( \pm )-HA-966 had no effect on overall severity of naloxone-precipitated opiate withdrawal. However, at the low dose $(3 \mathrm{mg} / \mathrm{kg})$, there was some enhancement of specific signs of withdrawal, including penile grooming and stretches. Whereas the effects of ( \pm )-HA-966 on naloxone-precipitated opiate withdrawal found in the present study were small, they are consistent with that expected of a glycine partial against and the role of glycine in naloxone-precipitated opiate withdrawal. In addition, the present study used the racemic mixture of $( \pm)-\mathrm{HA}-966$ that may have contributed to the weak effects observed on precipitated opiate withdrawal. Indeed, electrophysiologic and biochemical data suggest that the NMDA antagonistlike effects of HA-966 are due to the (+)-enantiomer (Singh et al. 1990). Future studies using different doses of resolved enantiomers of HA- 966 should be performed to further elucidate the role of glycine and of HA-966 in naloxone-precipitated opiate withdrawal.

An alternative mechanism underlying the effects of some of these agents in reducing the severity of naloxone-precipitated opiate withdrawal is through GABAergic systems. GABAergic systems are involved in withdrawal effects (e.g., Redmond and Krystal 1984). Although the mechanisms underlying felbamate are still largely unknown, it was originally speculated that its anticonvulsant effects may have been due to GABAergic mechanisms due to the similarity of these effects to those of benzodiazepines and barbiturates (e.g., Gordon et al. 1991). However, felbamate does not alter $\mathrm{GABA}_{\mathrm{A}}$ receptor binding nor affect chloride influx in GABA-mediated systems (Ticku et al. 1991).
GABAergic mechanisms may have been involved in the ( \pm )-HA-966 effects as the (-)-enantiomer of HA-966 does possess $\mathrm{GABA}$ B agonist-like properties (Singh et al. 1990). Thus, the results of the present study in which the racemic mixture of HA-966 was used may reflect the interaction of $\mathrm{GABA}_{\mathrm{B}}$ agonistlike effects with glycine partial agonist effects. At lower doses, these effects would, presumably, counter each other. This may help to explain the small effects seen on specific signs and the lack of effect seen in overall withdrawal severity in the present study.

The ratings of some withdrawal signs may have been reduced due to nonspecific effects that interfered with the expression of these behaviors. For example, sedation may have inhibited the expression of some signs, such as the motoric ones. Yet, little sedation was observed in these rats, except for some given the high dose of $( \pm)$-HA-966. And, the dose of this drug had no effect on the severity of naloxone-precipitated opiate withdrawal. Moreover, some withdrawal signs are expressed even under anesthesia (George Aghajanian, personal communication, April 1994). Thus, it is unlikely that the significant attenuations seen in the expression of naloxone-precipitated opiate withdrawal signs in the present study were due to inhibition caused by sedation.

There were some marked differences among the three studies on the expression of some of the withdrawal signs. Notably, diarrhea, body weight loss, salivation, and lacrimation were less severe in the felbamate groups compared to the D-cycloserine and HA-966 groups. Conversely, ratings of stretches were greater in the felbamate group compared to the other two agents. It is likely that the differences were due to the different vehicle used: polyethylene glycol for felbamate and saline for D-cycloserine and HA-966. Indeed, comparisons in the ratings of these signs across the two vehicle groups did show significant effects. Many of the withdrawal signs that showed vehicle differences, such as diarrhea and the consequent body weight loss, salivation, and lacrimation, have been suggested to be due to peripheral effects of opiate antagonists, rather than central effects (Maldonado and Koob 1993; Maldonado et al. 1992). The increased severity of stretches in the felbamate study is most likely due to the polyethylene glycol also, as occurrences of stretches were observed before the naloxone injection in this group.

Felbamate attenuated naloxone-precipitated opiate withdrawal signs that are thought to be mediated by central mechanisms and, possibly, through the PGi/LC system. First, the ratings of many secretory signs, such as diarrhea, salivation, and lacrimation, were not affected by felbamate. These signs are seen only after peripheral naloxone injections (Maldonado et al. 1992). Second, felbamate did reduce the occurrences of chews, teeth chatters, and penile grooming. Teeth chatters 
and chews are induced readily by infusions of the hydrophilic opiate antagonist, methylnaloxonium, into the brain regions such as the $L C$, periaqueductal gray matter, or lateral ventricle (Maldonado et al. 1992), and lesions of the LC reduce chews (Maldonado and Koob 1993). Other signs are elicited by methylnaloxonium infusions into the LC, including jumping (Maldonado et al. 1992), and LC lesions also attenuate occurrences of wet dog shakes and ptosis (Maldonado and Koob, 1993). In the present study, however, jumping was never exhibited and the frequency of wet dog shakes and ratings of ptosis were not attenuated significantly by felbamate or by the other drugs.

Overall, the results of the present study are consistent with previous work assessing the effects of manipulating the glutamate system in opiate withdrawal. For example, the noncompetitive excitatory amino acid antagonist, MK-801, attenuates the severity of naloxone-precipitated opiate withdrawal (Rasmussen et al. 1991a; Tanganelli et al. 1991; Higgins et al. 1992) and the development of morphine dependence as assessed by naloxone-precipitated withdrawal (Trujillo and Akil 1991). Kynurenic acid, a nonselective excitatory amino acid antagonist (Perkins and Stone 1982) has also been found to attenuate antagonist-precipitated opiate withdrawal when given systemically or centrally (Rasmussen et al. 1991b).

The results of the present study support the role of glycine in the expression of naloxone-precipitated opiate withdrawal signs. That the severity of this syndrome can be attenuated by the presumed glycine agent, felbamate, and by $\mathrm{D}$-cycloserine has important implications for the treatment of opiate abuse and withdrawal. Detoxification from chronic opiate use requires either a long-term withdrawal procedure (e.g., methadone tapering) or a short-term precipitation procedure (e.g., naltrexone induction). Having a pharmacologic agent that reduces withdrawal severity without untoward side effects would be an advancement in opiate detoxification treatment. Clonidine, an $\alpha_{2}$ agonist often used for opiate detoxification, is associated with sedative effects and greatly reduces heart rate and blood pressure. These effects make the use of clonidine for opiate detoxification difficult. The two agents tested in this study for which significant reductions in naloxoneprecipitated opiate withdrawal were found did not have sedative effects, at least at the doses assessed. Moreover, felbamate and the other agents assessed in the present study did not induce the unwarranted PCPlike behaviors that are often observed with noncompetitive NMDA antagonists. Whereas lack of sedation and PCPlike effects characterize the agents assessed in the present study, these agents are associated with some effects that may contraindicate their clinical use. Felbamate has recently been associated with aplastic anemia, and there have been reports of seizures and psychosis with clinical use of D-cycloserine. Nonetheless, either these drugs in particular or glycine antagonists or partial agonists in general may be useful medications for opiate abuse.

\section{ACKNOWLEDGMENTS}

This research was supported by grants from the National Institute on Drug Abuse, P50-DA04060 and DA08227, and by the Abraham Ribicoff Research Facilities, Connecticut Mental Health Center, State of Connecticut Department of Mental Health.

\section{REFERENCES}

Aghajanian GK (1978): Tolerance of locus coeruleus neurons to morphine and suppression of withdrawal response by clonidine. Nature 276:186-188

Aghajanian GK, Kogan JH, Moghaddam B (1994): Opiate withdrawal increases glutamate and aspartate efflux in the locus coeruleus: An in vivo microdialysis study. Brain Res 636:126-130

Akaoka H, Aston-Jones G(1991): Opiate withdrawal-induced hyperactivity of locus coeruleus neurons is substantially mediated by augmented excitatory amino acid input. J Neurosci 11:3,830-3,839

Blasig J, Herz A, Reinhold K, Zieglgansberge S (1973): Development of physical dependence on morphine in respect to time and dosage and quantification of the precipitated withdrawal syndrome in rats. Psychopharmacologia 33:19-38

Bowyer JF (1982): Phencyclidine inhibition of the rate of kindling development. Exp Neurol 75:173-175

Chronopoulos A, Stafstrom C, Thurber S, Hyde P, Mikati M, Holmes GL (1993): Neuroprotective effect of felbamate after kainic acid-induced status epilepticus. Epilepsia 34:359-366

Collingridge GL, Kehl SJ, McLennan H (1983): Excitatory amino acids in synaptic transmission in the Schaffer collateral-commissural pathway of the rat hippocampus. J Physiol (Lond) 334:34-36

Cornford EM, Young D, Paxton JW, Sofia RD (1992): Bloodbrain barrier penetration of felbamate. Epilepsia 33:944954

Danysz W, Essmann U, Bresink I, Wilke R (1993): Glutamate antagonists have different effects on spontaneous locomotor activity in rats. Pharmacol Biochem Behav 48: $111-118$

Emmett MR, Mick SJ, Cler JA, Rao TS, Iyengar S, Wood PL (1991): Actions of D-cycloserine at the N-methyl-D-asparate-associated glycine receptor site in vivo. Neuropharmacology 30:1,167-1,171

Ennis M, Aston-Jones G (1988): Activation of locus coeruleus from nucleus paragiganto-cellularis: A new excitatory amino acid pathway in brain. J Neurosci 8:3,644-3,657

Fletcher EJ, Lodge D (1988): Glycine reverses antagonism of N-methyl-D asparate (NMDA) by 1-hydroxy-3-aminopyrroidone-2 (HA-966) but not by D-2-amino-5-phosphono- 
valerate (D-AP5) on rat cortical slices. Eur J Pharmacol 151:161-162

Foster AC, Kemp JA (1989): HA-966 antagonizes N-methyl$D$-asparate receptors through a selective interaction with the glycine modulatory site. J Neurosci 9:2,191-2,196

Gordon R, Gels M, Diamantis W, Sofia RD (1991): Interaction of felbamate and diazepam against maximal electroshock seizures and chemoconvulsants in mice. Pharmacol Biochem Behav 40:109-113

Harris EW, Ganong AH, Cotman CW (1984): Long-term potentiation in the hippocampus involves activation of $N$-methyl-D-aspartate receptors. Brain Res 323:132-137

Higgins GA, Nguyen P, Sellers EM (1992): The NMDA antagonist dizocilpine (MK801) attenuates motivational as well as somatic aspects of naloxone-precipitated opioid withdrawal. Life Sci 50:PL167-PL172

Hood WF, Compton RP, Monahan JB (1989): D-cycloserine: a ligand for the N-methyl-D-aspartate coupled glycine receptor has partial agonist characteristics. Neurosci Lett 98:91-95

Johnson JW, Ascher P (1987): Glycine potentiates the NMDA response in cultured mouse brain neurons. Nature 325:529-531

Kemp JA, Leeson PD (1993): The glycine site of the NMDA receptor-Five years on. Trends Pharmacol Sci 14:20-25

Kleinschmidt A, Bear MF, Singer W (1987): Blockade of "NMDA" receptors disrupts experience-dependent plasticity of kitten striate cortex. Science 238:355-358

Kosten TA (1990): Cocaine attenuates the severity of naloxoneprecipitated opiate withdrawal. Life Sci 47:1,617-1,623

Leepik IE, Dreifuss FE, Pledger GW, Graves NM, Santilli N, Drury I, Tsay JY, Jacobs MP, Bertram E, Cereghino JJ, Cooper G, Sahlroot JT, Sheridan P, Ashworth M, Lee SI, Sierzant TL (1991): Felbamate for partial seizures: Results of a controlled clinical trial. Neurology 41:1,7851,789

Lincoln J, Coopersmith R, Harris EW, Cotman CW, Leon M (1988): NMDA receptor activation and early olfactory learning. Dev Brain Res 39:309-312

Maldonado R, Koob GF (1993): Destruction of the locus coeruleus decreases physical signs of opiate withdrawal. Brain Res 605:128-138

Maldonado R, Stinus L, Gold LH, Koob GF (1992): Role of different brain structures in the expression of the physical morphine withdrawal syndrome. J Pharmacol Exp Ther 261:669-677

McCabe RT, Wasterlain CG, Kucharczyk N, Sofia RD, Vogel JR (1993): Evidence for anticonvulsant and neuroprotectant action of felbamate mediated by strychnine-insensitive glycine receptors. J Pharmacol Exp Ther $264: 1,248$ 1,252

McDonald JW, Uckele J, Silverstein FS, Johnston MV (1989): HA-966 (1-hydroxy-3-aminopyrrolidone-2) selectively reduces $\mathrm{N}$-methyl-D-aspartate (NMDA)-mediated brain damage. Neurosci Lett 104:167-170

McNamara JO, Russell RD, Rigsbee L, Bonhaus DW (1988): Anticonvulsant and antiepileptogenic action of MK-801 in the kindling and electroshock models. Neuropharmacology 27:563-568

Monahan JB, Handelmann GE, Hood WF, Cordi AA (1989)
D-Cycloserine, a positive modulator of the N-methyl-Dasparate receptor, enhances performance of learning tasks in rats. Pharmacol Biochem Behav 34:649-653

Morris RGM, Anderson E, Lynch GS, Baudry M (1986): Selective impairment and blockade of long-term potentiation by an N-methyl-D-aspartate receptor antagonist, AP5. Nature 319:774-776

Perkins MN, Stone TW (1982): An iontophoretic investigation of the actions of convulsant kynurenines and their interactions with the endogenous excitant quinolinic acid. Brain Res 247:184-187

Rasmussen K, Aghajanian GK (1989): Withdrawal-induced activation of locus coeruleus neurons in opiate-dependent rats: Attenuation by lesions of the nucleus paragigantocellularis. Brain Res 505:346-350

Rasmussen K, Fuller RW, Stockton ME, Perry KW, Swinford RM, Ornstein PL (1991a): NMDA receptor antagonists suppress behaviors but not norepinephrine turnover or locus coeruleus unit activity induce by opiate withdrawal. Eur J Pharmacol 197:9-16

Rasmussen K, Krystal JH, Aghajanian GK (1991b): Excitatory amino acids and morphine withdrawal: Differential effects of central and peripheral kynurenic acid administration. Psychopharmacology 105:508-512

Rauschecker JP, Hahn S (1987): Ketamine-xylazine anaesthesia blocks consolidation of ocular dominance changes in kitten visual cortex. Nature 326:183-185

Redmond DE Jr, Krystal JH (1984): Multiple mechanisms of withdrawal from opioid drugs. Ann Rev Neurosci 7: $443-478$

Ritter FJ, Leepik IE, Dreifuss FE, Rak I, Santilli N, Homzie $R$, Dodson WE, Glauser TA, Sackellares C, Olson L, Garafolo EA, Sachdeo R, Kramer LD, Rosenberg A, Sachdeo S (1992): Felbamate monotherapy: Controlled trial in patients with partial onset seizures. Ann Neurol 32: 386-392

Shields WD, French J, Sperling M, Kramer LD, Kamin M, Rosenberg A, Shumaker R, Perhach JL, Dix R (1993): Efficacy of felbamate in childhood epileptic encephalopathy (Lennox-Gastaut syndrome). N Engl J Med 328: 29-33

Schuster GM, Schmidt WJ (1992): D-cycloserine reverses the working memory impairment of hippocampal-lesioned rats in a spatial learning task. Eur J Pharmacol 224:97-98

Simon RP, Swan JH, Griffiths T, Meldrum BS (1984): Blockade of N-methyl-p-aspartate receptors may protect against ischemic damage in the brain. Science 226:850-852

Singh L, Donald AE, Foster AC, Hutson PH, Iversen LL, Iversen SD, Kemp JA, Leeson PD, Marshall GR, Oles RJ, Priestley T, Thorn L, Tricklebank MD, Vass CA, Williams BJ (1990): Enantiomers of HA-966 (3-amino-1-hydroxypyrrolid-2-one) exhibit distinct central nervous system effects: (+)-HA-966 is a selective glycine/ $\mathrm{N}$-methyl-D-asparate receptor antagonist, but (-)-HA-966 is a potent y-butyro-lactonelike sedative. Proc Natl Acad Sci 87: $347-351$

Swinyard EA, Sofia RD, Kupferberg HJ (1986): Comparative anticonvulsant activity and neurotoxicity of felbamate and four prototype antiepileptic drugs in mice and rats. Epilepsia 27:27-34

Tanganelli S, Antonelli T, Morari M, Bianchi C, Beani L (1991): 
Glutamate antagonists prevent morphine withdrawal in mice and guinea pigs. Neurosci Lett 122:270-272

Thomas AM (1990): Glycine is a coagonist at the NMDA receptor/channel complex. Prog Neurobiol 35:53-74

Theodore WH, Raubertas RF, Porter RJ, Nice F, Devinsky O, Reeves P, Bromfield E, Ito B, Balish M (1991): Felbamate: A clinical trial for complex partial seizures. Epilepsia 32:392-397

Ticku MK, Kamatchi GL, Sofia RD (1991): Effects of felbamate on $\mathrm{GABA}_{\mathrm{A}}$ receptor system. Epilepsia 32:398-391

Trujillo KA, Akil H (1991): Inhibition of morphine tolerance and dependence by the NMDA receptor antagonist MK801. Science 251:85-87

Wallis RA, Panizzon KL, Fairchild MD, Wasterlain CG (1990): Felbamate is a potent antihypoxic agent in the hippocampal slice. Neurology 40 (suppl 1):193
Wasterlain CG, Adams LM, Hattori H, Schwartz PH (1992): Felbamate reduces hypoxic-ischemic brain damage in vivo. Eur J Pharmacol 212:275-278

Watson GB, Bolanowski MA, Baganoff MP, Deppeler CL, Lanthorn TH (1990): D-cycloserine acts as a partial agonist at the glycine modulatory site of the NMDA receptor expressed in Xenopus oocytes. Brain Res 510:158-160

White HS, Wolf HH, Swinyard EA, Skeen GA, Sofia RD (1992): A neuropharmacologic evaluation of felbamate as a novel anticonvulsant. Epilepsia 33:564-572

Willets J, Balster RL, Leander JD (1990): The behavioral pharmacology of NMDA receptor antagonists. Trends Pharmacol Sci 11:423-428

Zhang T, Feng Y, Rockhold RW, Ho IK (1994): Naloxoneprecipitated morphine withdrawal increases pontine glutamate levels in the rat. Life Sci 55:PL25-PL31 